\title{
MISSED GALLSTONES IN THE BILE DUCT AND ABDOMINAL CAVITY: A CASE REPORT
}

doi: $10.1590 / \mathbf{S 1 8 0 7 - 5 9 3 2 2 0 0 8 0 0 0 4 0 0 0 2 7}$

\section{Oktay Irkorucu, Oge Tascilar, Ali Ugur Emre, Güldeniz Karadeniz Çakmak, Bülent Hamdi Ucan, Mustafa Comert}

\section{INTRODUCTION}

Laparoscopic cholecystectomy is considered the gold standard surgical intervention for the treatment of symptomatic gallstones. ${ }^{1}$ Gallbladder perforation (10$40 \%$ ) and stone spillage (6-30\%) are the two complications encountered most often during the dissection and removal of the gallbladder in LC. ${ }^{2}$ Gallstone spillage was initially considered to be a benign event with no serious squeal. However, there have been reports of serious complications due to spilled gallstones during LC. ${ }^{3-6}$ The present report present an extremely rare case of missed gallstones with an intra-abdominal abscess complicated by erosion and fistula of the bile duct due to stones retained in the abdominal cavity during LC.

\section{CASE REPORT}

A 29 year-old woman was admitted to the hospital with a 4-day history of fatigue, nausea, vomiting, and fever. Her physical examination was unremarkable except for mild abdominal distention without rebound or guarding. The results of standard laboratory tests were within normal ranges, except for the leukocyte count (23000 cells/UL). The computerised tomography and ultrasonographic examination of the abdomen revealed a complex infra-hepatic abscess $(5 \mathrm{x}$ $7 \times 9 \mathrm{~cm}$ ) with a calcified density observed within the lateral margin (Figure 1). The patient's previous medical history revealed that she had medication-controlled diabetes mellitus and had undergone LC in another hospital four weeks prior to hospitalization at our facility. According to consultation with infectious disease specialists, the patient was placed on

Department of Surgery, Zonguldak Karaelmas University, School of Medicine, Kozlu-Zonguldak, Turkey.

Email: oktaytip@yahoo.com

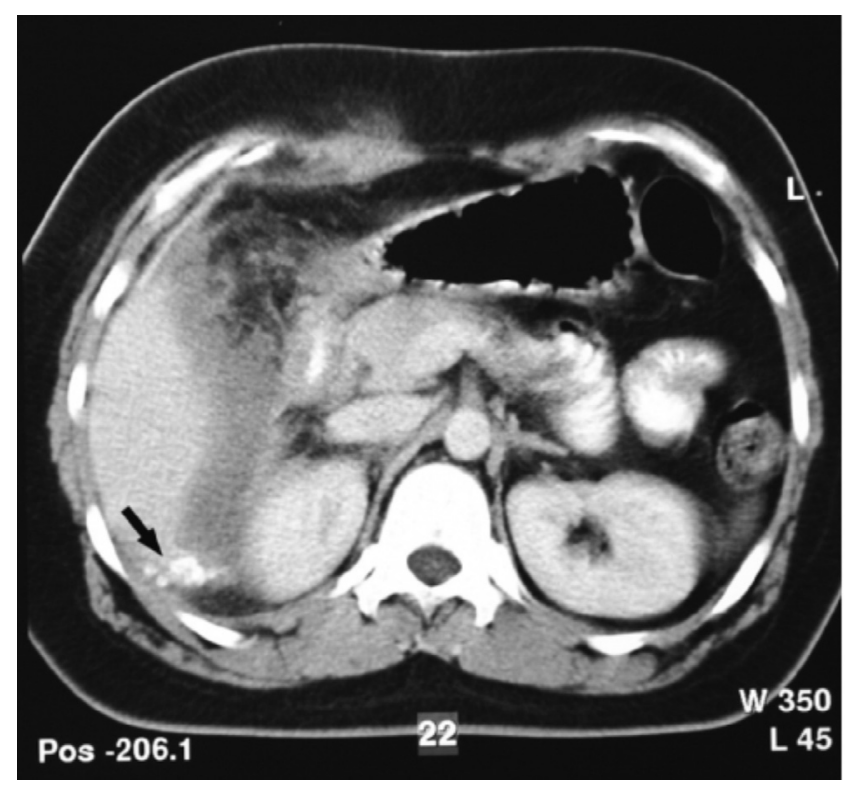

Figure 1 - The computed tomography of the abdomen revealed a complex infra-hepatic abscess $(5 \times 7 \times 9 \mathrm{~cm}$ ) showing calcified density (gallstones) within the lateral margin (arrow)

imipenem and examined by gastroenterologists.

Since upper and lower gastrointestinal endoscopy revealed no significant findings, open drainage of the abscess was chosen as the treatment. Following a right subcostal mini-laparatomy, the abscess was drained, and 16 pigment gallstones, each 7-8 $\mathrm{mm}$ in size, were evacuated. The abscess cavity was washed out and a large drain was placed. An erosion area on the common bile duct without a leakage was observed. On the first postoperative day, bile drainage into the infra-hepatic abdominal drain was identified. Endoscopic retrograde cholangiopancreatography (ERCP) visualised a leakage near the cystic duct with retained stones in the common bile duct (Figure 2). The calculus was evacuated following sphincterotomy, and a drainage stent/catheter was inserted into the common bile duct. 


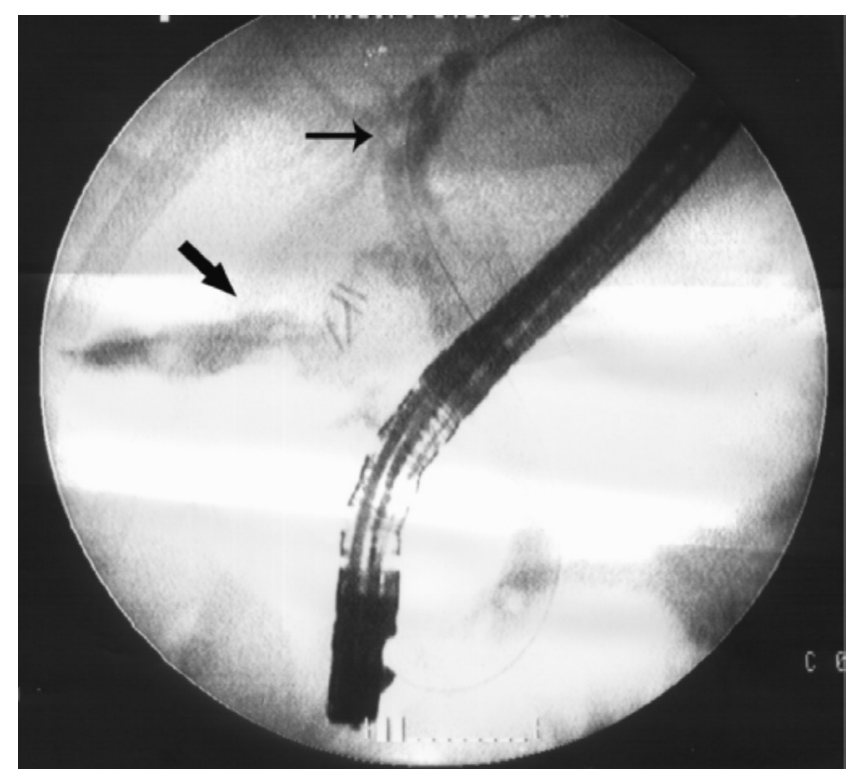

Figure 2- The large arrow indicates the bile duct fistulae, while the thin arrow indicates stones in the common bile duct

The patient tolerated the procedure well and had an uneventful clinical course. The microbiological evaluation of the drained material was positive for Klebsiella pneumoniae and Escherichia coli. The review of the previous operative record confirmed that iatrogenic gallbladder perforation and gallstone spillage had occurred during the procedure.

\section{DISCUSSION}

LC is currently regarded as the gold standard treatment for symptomatic gallstones. Gallbladder perforation (10$40 \%$ ) and stone spillage (6-30\%) are the two most common complications of LC that arise during the dissection (75\%) and removal $(25 \%)$ of the gallbladder. ${ }^{2-5}$ In the majority of cases, these stones usually cause no problem and remain benign. However, $0.08-0.3 \%$ of patients develop complications as a result of these stones, and this percentage increases to $7 \%$ in the case of unretrieved peritoneal gallstone..$^{3-5}$ In the literature, the mean time between LC and reintervention is reported to be 10.4 months, with a range of 10 days to 20 years. ${ }^{3-5}$ In our case, the duration between LC and intra-abdominal abscess formation was one month.

Various studies have reviewed the risk factors for iatrogenic gallbladder perforation in LC. These risk factors include surgeon experience, difficulty of the operation (cholecystitis), adhesions in the right upper quadrant of abdominal cavity, preoperative pain lasting longer than 96 hours, palpable gallbladder in the preoperative period, obesity, older age, and male sex..,5,7-9 In the present case, aside from the fact that the patient was obese, we encountered adhesions in the right upper quadrant, which were probably due to her previous operation for chronic cholecystitis. In our opinion, an experienced surgeon should be attentive to the risk of perforation, particularly in highrisk patients mentioned above.

The significant risk factors for complications due to peritoneal gallstones include older age, male sex, acute cholecystitis, spillage of pigment stones, number $(>15)$ or size $(>1.5 \mathrm{~cm})$ of the stones, and perihepatic localization of the spilled stones. In our case, 16 pigment gallstones, all of which were located in the subhepatic region with a diameter of 7-8 $\mathrm{mm}$, were removed from the abscess cavity. Brockmann and Cohen et al. stated that gallstones around the liver, especially in cases where they are "sandwiched" between the liver surface and the diaphragm, may escape from the intra-abdominal clearing mechanism provided by the greater omentum and intestinal immune system. This may explain the abscess formation in our case. ${ }^{2,10}$ In cases of pigment stones, $83 \%$ show bacterial contamination, which may also be responsible for abscess formation in the present case. ${ }^{2,5,11,12}$

The most common complication of intraperitoneal gallstones is abscess formation,,$^{1,4-6,12,13}$ accounting for $60 \%$ of complications. ${ }^{2}$ The most common pathogen reported is Escherichia coli, which is consistent with our microbiological evaluation of the present case. ${ }^{1,4,5}$ The other rare complications of LC are as follows: ovarian stone implantation, tubalithiasis, dyspareunia, chronic pelvic pain, small bowel obstruction, and enteric fistulae. Biliary complications including biliary obstruction, cholangitis, jaundice, and biliary-cutaneus fistulae may be a result of extrinsic pressure on the biliary tree..$^{1,2,-9}$ Cavitary abscess as a result of spilled gallstones has previously been reported, nevertheless little has been noted about the relationship between abscess process and fistulae formation. Moreover, potential role of endoscopy in the management of these complications has not been absolutely clarified yet. In the present case, the erosion of the bile duct leading to a biliary fistulae can be attributed to the spilled gallstones at the time of the LC and with the resulting acute inflammation. Nevertheless, occlusion of the site of communication by either debris or edema within the first days following surgery may have caused the delayed drainage flow and resulting delay in detecting fistulae.

To minimize the above-mentioned complications, proper dissection is absolutely required. In the case of gallbladder perforation, the correct use of suction devices and an endo-bag is necessary to minimize bile and gallstone spillage. If possible, the hole in the gallbladder should be closed by either grasp forceps or by an endoclip and endoloop. The abdominal cavity should be thoroughly irrigated immediately to reduce the spillage of bile and 
gallstones. ${ }^{1,2}$ The therapeutic use of antibiotics in gallbladder perforation without the spillage of gallstones is obligatory. ${ }^{1,5}$ Whenever gallstone spillage occurs, stone collection can be facilitated by the carefull use of an intra-abdominal bag and a laparoscopic grasper with a $10-\mathrm{mm}$ suction device, or a "shuttle" stone collector. ${ }^{1-5,14}$ Every effort should be made to remove spilled gallstones to prevent further complications; nevertheless, conversion to open surgery is not mandatory. The appropriate treatment is almost always drainage, which may require a laparatomy or laparoscopy. Although percutaneous drainage is a minimally invasive procedure that is effective at resolving acute symptoms, abscess recurrence is extremely likely if the gallstones within the cavity are not removed. ${ }^{1,3,4-6}$

In our patient, open drainage of the abscess and removal of the retained gallstones via a mini-laparatomy was for the chosen treatment. In addition, the difference between the drainage of an uncomplicated abscess and an abscess with fistulae should be emphasized. Since the abscess cavity itself may heal within a few days after drainage, the fistulae often takes a longer time to close. Accordingly, the mechanical principles influencing the healing process of the fistulae have been clearly established by surgical experience. In general, the presence of a distal obstruction will impair the healing of the fistulae, although such an obstruction can also impair healing. Thus, gastrostomy, jejunostomy, and T-tubes are often removed without leaks. Similar mechanics are valid for successful fistulae drainage after the abscess is drained; the biliary tree preferentially drains internally, leading eventually to the healing of the iatrogenic hole or tear. However, in case of a stone in the distal bile duct, the pressure remains high in the system, and the fistulae leak will continue to drain externally. In the present case, the stones were evacuated by sphincterotomy, and a drainage catheter was inserted into the common bile duct in order to relieve intraluminal pressure. As a result, the patient had an uneventful clinical course.

The present study is a example of how gallbladder perforation and stone spillage can cause hazardous complications. Every effort should be made to avoid perforation of the gallbladder during its dissection-this is the first and most important step in prevention. In the presence of gallbladder perforation and gallstone spillage, removing the spilled gallstones may prevent forthcoming complications. As in the present case, maintaining and consulting detailed patient records can provide valuable guidance in treatment decisions.

\section{REFERENCES}

1. Zehetner J, Shamiyeh A, Wayand W. Lost gallstones in laparoscopic cholecystectomy: all possible complications. Am J Surg. 2007;193:738 .

2. Brockmann JG, Kocher T, Senninger NJ, Schürmann GM. Complications due to gallstones lost during laparoscopic cholecystectomy. Surg Endosc. 2002;16:1226-32.

3. Koç E, Suher M, Öztuğut ŞU, Ensari C, Karakut M, Özlem N. Retroperitoneal abscess as a late complication following laparoscopic cholecystectomy. Med Sci Monit. 2004;10:CS27-9.
4. Sathesh-Kumar T, Saklani AP, Vinayagam R, Blackett RL. Spilled gall Stones during laparoscopic cholecystectomy: a review of the literature. Postgrad Med J. 2004;80:77-9.

5. Woodfield JC, Rodgers M, Windsor JA. Peritoneal gallstones following laparoscopic cholecystectomy. Incidence, complications, and management. Surg Endosc. 2004;18:1200-07.

6. Hawasali A, Schroder D, Rizzo J, Thusay M, Takach T, Thao U et al. Remote complications of spilled gallstones during laparoscopic cholecystectomy: causes, prevention and management. J Laparoendosc Adv Surg Tech. 2002;12:123-27. 
7. Assaff Y, Matter I, Sabo E, Mogilner JG, Nash E, Abrahamson J et al. Laparoscopic cholecystectomy for acute cholecystitis and the consequences of gallbladder perforation, bile spillage, and "loss" of stones. Eur J Surg.1998;164:425-31.

8. Rice DC, Memon MA, Jamison RL, Agnessi T, Ilstrup D, Bannon MB et al. Long-term consequences of intraoperative spillage of bile and gallstone during laparoscopic cholecystectomy. J Gastrointest Surg. 1997;1:85-101.

9. Sarli L, Pietra N, Costi R, Grattarola M. Gallbladder perforation during laparoscopic cholecystectomy. World J Surg. 1999;23:1186-90.

10. Cohen RV, Pererira PRB, Barros MV. Is the retrieval of lost peritoneal gallstones worthwhile? Surg Endosc. 1994;8:1360.
11. Yerdel MA, Alacayir I, Malkoc U, Baba F, Erverdi N, Pak I et al. The fate of intraperitoneally retained gallstones with different morphologic and microbiologic characteristics: an experimental study. Laparoendosc Adv Surg Tech. 1997;7:87-94.

12. Gürleyik E, Gürleyik G, Yücel O, Unalmiser S. Does chemical composition have an influence on the fate of intraperitoneal gallstone in rat? Surg Laparosc Endosc. 1998;8:113-16.

13. Zülfikaroglu B, Ozalp N, Ozmen M, Koc M. What happens to the lost gallstone during laparoscopic cholecystectomy. Surg Endosc. 2003; 17:158.

14. Klaiber C, Metzger A, Saager C. The "shuttle" stone collector - a new device for collecting lost gallstones in laparoscopic cholecystectomy. Surg Endosc. 1992;6:84. 